\title{
ACTIVATED AND MICRONIZED ZEOLITE IN THE MODULATION OF CELLULAR OXIDATIVE STRESS IN MEXICAN SMOKERS: A RANDOMIZED CLINICAL TRIAL
}

\author{
Alfonso Atitlán-Gil ${ }^{1,2}$, Martín M. Bretón-de la Loza3, José C. Jiménez-Ortega ${ }^{4}$, \\ Helen Belefant-Miller ${ }^{5}$ and Gabriel Betanzos-Cabrera ${ }^{6 *}$ \\ ${ }^{1}$ Innovation Department, Granding International, SA de CV, Jiutepec, Mor., Mexico; ${ }^{2}$ Research Department, \\ Coordinación de Investigación del Área de Ciencias de la Salud, Centro Universitario Siglo XXI, Pachuca, Hgo., Mexico; \\ ${ }^{3}$ Department of Translational Investigation, Facultad de Nutrición, Universidad Autónoma del Estado de Morelos, \\ Cuernavaca, Mor., Mexico; ${ }^{4}$ Department of Molecular Biology, Centro Médico Nacional de Biología Molecular, Pue., \\ Mexico; ${ }^{5}$ Dale Bumpers National Rice Research Center, Agricultural Research Service, USDA, Stuttgart, USA; \\ ${ }^{6}$ Department of Nutrition and Clinical Toxicology, Área Académica de Nutrición, Instituto de Ciencias de la Salud, \\ Universidad Autónoma del Estado de Hidalgo, Pachuca, Hgo., Mexico
}

\begin{abstract}
Background: Activated and micronized zeolites are used as detoxifying agents in humans. Detoxification is attributed to their ability to reduce lipid peroxidation by scavenging free radicals. Objective: To evaluate activated and micronized zeolites as modulators of cellular oxidative stress in Mexican smokers without lung diseases. Methods: Randomized clinical trial. Subjects were randomly divided into three groups: activated and micronized zeolites, $n=29$; vitamin $E$, an accepted antioxidant, $n=29$; and maltodextrin as control, $\mathrm{n}=27$. Each group received the corresponding supplementation, dissolved in water, once a day for 30 days as follows: activated and micronized zeolites, $5.4 \mathrm{~g}$ activated and micronized zeolite; vitamin E, 400 mg D-alpha tocopheryl acetate; and maltodextrin, $250 \mathrm{mg}$ of maltodextrin. The thiobarbituric acid reactive substances assay was used to screen for lipid peroxidation. Catalase activity, plasma antioxidant capacity, and hydrogen peroxide levels were also measured. Results were analyzed by a one-way ANOVA and post hoc test of Bonferroni. Results: Subjects administered activated and micronized zeolites had equivalent antioxidant activities as subjects administered vitamin E. Conclusions: Activated and micronized zeolites may be useful as a modulator of oxidative stress in smokers. However, inclusion of a comparison group of non-smokers would be useful in future studies to assess the degree to which zeolites reverse the oxidant stress. (REV INVES CLIN. 2017;69:146-51)
\end{abstract}

Key words: Activated micronized zeolite. Oxidative stress. Smoking. Catalase. Total antioxidant power.

Corresponding author:

*Gabriel Betanzos-Cabrera

Abasolo, 600

C.P. 42000, Pachuca de Soto, Hgo., México

Received for publication: 15-12-2016

E-mail: gbetanzo@uaeh.edu.mx

Accepted for publication: 10-03-2017 


\section{INTRODUCTION}

Cigarette smoking is a major environmental stress factor since smoking enhances reactive oxygen species (ROS) formation, which becomes a significant oxidative stress in vivo ${ }^{1}$. A smoker is exposed to large amounts of free radicals in each puff, and this exposure is further enhanced when the smoker holds the smoke in the body ${ }^{1,2}$. ROS cause oxidative damage to cells and are generated by various sources, even under normal conditions such as regular cell metabolism when cells maintain a balance between oxidants and antioxidants ${ }^{1-3}$. However, external factors can increase ROS production ${ }^{3}$. Oxidative stress is a condition wherein the cellular production of ROS exceeds the physiological capacity of the antioxidant defense systems to inactivate them ${ }^{3,4}$. In humans, the most common oxidants are ROS and molecular precursors of ROS such as hydrogen peroxide $\left(\mathrm{H}_{2} \mathrm{O}_{2}\right)^{3}$. ROS cause oxidation of lipids and lipoproteins, DNA, proteins, and other molecules, altering cellular functions and are probably the cause of a number of chronic diseases $^{2,4-6}$.

Catalase, an antioxidant enzyme present in most aerobic organisms, catalyzes the dismutation of $\mathrm{H}_{2} \mathrm{O}_{2}$ into water and oxygen ${ }^{3,5}$. The human body has several enzymes that chemically decompose $\mathrm{H}_{2} \mathrm{O}_{2}$, including catalase, peroxidases, and peroxiredoxins ${ }^{3}$. Lipid peroxidation of cell membranes, which produces malondialdehyde (MDA), is considered a good indicator of oxidative stress ${ }^{6}$. The antioxidant power capacity of a system is measured by the antioxidant capacity of plasma systems to inhibit $50 \%$ of the formation of thiobarbituric acid reactive substances (TBARS) $3,4,6$.

Vitamins $E$ and $C$ (ascorbic acid) are two of many antioxidant molecules that can inactivate ROS ${ }^{3,4}$. The reduction in vitamin $\mathrm{E}$ levels is accelerated in cigarette smokers due to their increased oxidative stress; however, vitamin E levels can be normalized by vitamin $C$ supplementation. There is evidence that ascorbic acid supplementation ( $500 \mathrm{mg}$, twice daily for two weeks) would lead to normal rates in smokers' plasma alpha- and gamma-tocopherol disappearance ${ }^{7}$.

Zeolites are a group of aluminosilicates that exhibit diverse biological activities and have found uses as adjuvant therapy in anticancer therapy, adjuvant for vaccines, treatment of heartburn, and as antidiarrheal agents ${ }^{8-17}$. Natural zeolites are hydrated porous volcanic microcrystals formed mainly of $\mathrm{AlO}_{4}$ and $\mathrm{SiO}_{4}$, which have defined shapes resulting from tetrahedral building blocks connected through $\mathrm{O}_{2}$ atoms. Their open structure can integrate a wide variety of cations, such as $\mathrm{Na}^{+}, \mathrm{K}^{+}, \mathrm{Ca}^{2+}$, and $\mathrm{Mg}^{2+}$, based on a size exclusion process derived from the regular pore structure at the molecular level ${ }^{18-20}$. Clinoptilolite is a natural zeolite with a particular three-dimensional structure that endows it with specific physicochemical properties that include ion-exchange capacity, absorbency, size-exclusion framework, as well as cataIytic properties ${ }^{19,20}$. Activated and micronized zeolites are detoxifying agents because of their selective binding of heavy metals, $\mathrm{O}_{2}$, and ROS. Various studies have shown that these hydrated aluminosilicates have no toxic effects in either humans or animals ${ }^{8-10,14,15,21}$. Thus, we hypothesized that zeolites could provide a beneficial function of modulating cellular oxidative stress in smokers.

\section{MATERIALS AND METHODS}

\section{Materials}

The natural zeolite Klinobind ${ }^{\circ}$ (kindly donated by Granding International, SA de CV, Jiutepec, Morelos, Mexico) was activated and micronized by mechanical micronization, and tribochemical and thermal activation. Particle size was D90 1-11 $\mu \mathrm{m}$ and the specific surface area, as measured by the Brunauer-Emmett-Teller method, was $27 \mathrm{~m}^{2} / \mathrm{g}^{22}$. Vitamin $\mathrm{E}$, in the water-soluble form of D-alpha tocopheryl acetate (Astroquim, SA de CV, Ecatepec, Mexico), and maltodextrin (Amfher Foods, SA de CV, Mexico City, Mexico) were used as positive and negative controls, respectively.

\section{Study design and subjects}

This study was a randomized, double-blind, controlled trial. Smokers without lung diseases were randomized to receive, during 30 days, one of three treatments: activated and micronized zeolite (ZAM), vita$\min \mathrm{E}$, or maltodextrin. The antioxidant capacity of plasma was tested at the beginning and end of the trial. We enrolled smokers, aged 19-60 years, from the local community in Pachuca, state of Hidalgo, Mexico. Subjects were included if they had smoked 
for 2-37 years and smoked 8-29 cigarettes per day. Subjects with lung disease or any diseases, including acute infections or chronic illnesses, were eliminated after the initial clinical evaluation performed by physicians. Other exclusion criteria were the use of antioxidant supplementation or any drug containing antioxidants. The study was performed in accordance with the appropriate version of the 1964 Declaration of Helsinki and under the Law of General Health of Mexico. The Ethics Committee of Centro Médico Nacional de Biología Molecular approved the study protocol (register number KB-002-2012). A signed consent form was obtained from all participants.

\section{Treatments}

During the 30 days of the study, subjects were required to maintain their usual lifestyle and diet. To ensure that subjects could not distinguish zeolite from vitamin $\mathrm{E}$ and the control maltodextrin (polysaccharide that is used as a food additive), a commercial orange flavored powder (ML-G1-001 Doehler Mexico S.A. de C.V) was used to provide color and flavor to the three treatments. Clinical interviews were given by two physicians who were blind to the study's objective. Likewise, two nutritionists participated in the assignment of treatments to the groups, but did not meet the subjects. The investigator who analyzed the samples also never had contact with the subjects. The number of subjects per group was: $Z A M, n=29$; vitamin $E$, $\mathrm{n}=29$; and maltodextrin (MALTD), $\mathrm{n}=27$. The dose of ZAM was calculated based on a previous report by Dogliotti, et al. ${ }^{23}$. Subjects took the supplements dissolved in water every morning before the intake of any food or beverage during 30 days, as follows: ZAM, $5.4 \mathrm{~g}$ of activated and micronized zeolite; vitamin E, $400 \mathrm{mg}$ of D-alpha tocopheryl acetate; and MALTD, $250 \mathrm{mg}$ of maltodextrin.

\section{Biochemical analyses}

On days 0 and 30 of the intervention, blood samples were obtained by venipuncture after an overnight fast. The blood was immediately centrifuged at $4,000 \mathrm{rpm}$ for 10 minutes and the serum samples were separated into aliquots and frozen at $-70{ }^{\circ} \mathrm{C}$ until tested.

Four different tests for antioxidant activity were utilized. All of them were assayed in microtiter plates using commercial enzymatic colorimetric kits (Bioassay
Systems, Hayward, CA): Plasma antioxidant capacity (QuantiChrom ${ }^{\mathrm{TM}}$ DTAC-100), catalase activity (EnzyChrom $^{\text {TM }}$ ECAT-100), $\mathrm{H}_{2} \mathrm{O}_{2}$ (QuantiChrom ${ }^{\text {TM }}$ DIOX-250), and the thiobarbituric acid reactive substances (TBARS) assay (QuantiChrom ${ }^{\text {TM }}$ DTBA-100). Changes in $\mathrm{H}_{2} \mathrm{O}_{2}$ levels were directly measured, and lipid peroxidation was determined by measuring the inhibition of the formation of TBARS. Absorbance was measured in a spectrophotometer (ATI-Unicam 300, Cambridge, UK). If necessary, samples were diluted in a buffer and results were multiplied by the dilution factor. Each experiment was performed in triplicate.

\section{Statistical analysis}

Results were expressed as mean \pm SD of the value at 30 days minus the value at 0 time in each subject. The Kolmogorov-Smirnov test was performed to ensure that the data distribution was equivalent among the test groups. The Bonferroni test was used to compare the means after rejecting the null hypothesis of equality of means by a one-way ANOVA. Differences were considered significant at $p<0.05$. Statistical analysis was performed with SPSS v.12.0 (IBM).

\section{RESULTS}

A total of 85 smokers, 49 male and 36 female, participated in the trial. The baseline characteristics are described in table 1. All groups had similar values and there were no statistically significant differences between the test groups.

As expected, no changes were apparent in the subjects treated with the control compound MALTD in their plasma antioxidant capacity (Fig. 1), catalase levels (Fig. 2), hydrogen peroxide levels (Fig. 3), or lipid peroxidation activity (Fig. 4). The administration of either the standard antioxidant vitamin $\mathrm{E}$ or the test detoxifying agent ZAM resulted in large increases in the amount of antioxidants present in the plasma (Figs. 1 and 2) and decreases in ROS (Fig. 3) and oxidative stress (Fig. 4).

The ZAM was even slightly more effective than vitamin $E$ in raising the level of antioxidant capacity of the plasma (Figs. 1 and 2). ZAM also decreased $\mathrm{H}_{2} \mathrm{O}_{2}$ levels (Fig. 3 ) and lipid peroxidation activity (Fig. 4) to nearly those of the vitamin $E$ treatment. 
Table 1. Baseline data of treatment groups

\begin{tabular}{|c|c|c|c|}
\hline & $\begin{array}{c}\text { ZAM } \\
(n=29)\end{array}$ & $\begin{array}{c}\text { Vit E } \\
(n=29)\end{array}$ & $\begin{array}{l}\text { MALTD } \\
(n=27)\end{array}$ \\
\hline \multicolumn{4}{|l|}{$\overline{\text { Sex }}$} \\
\hline Female & 12 & 14 & 10 \\
\hline Male & 17 & 15 & 17 \\
\hline Age, mean y \pm SD & $35 \pm 13$ & $28 \pm 11$ & $29 \pm 12$ \\
\hline \# Cigarettes/day \pm SD & $20 \pm 7$ & $19 \pm 8$ & $18 \pm 8$ \\
\hline Smoking time, $y \pm S D$ & $14 \pm 12$ & $10 \pm 11$ & $10 \pm 10$ \\
\hline \multicolumn{4}{|l|}{ Plasma antioxidant } \\
\hline Capacity Trolox $(\mathrm{mM}) \pm \mathrm{SD}$ & $1,232.5 \pm 250.1$ & $1,227.1 \pm 313.0$ & $1,152.4 \pm 283.5$ \\
\hline Catalase Activity $(U / L) \pm S D$ & $24.9 \pm 7.9$ & $26.2 \pm 8.8$ & $21.4 \pm 5.8$ \\
\hline $\mathrm{H}_{2} \mathrm{O}_{2}(\mathrm{mg} / \mathrm{dl}) \pm \mathrm{SD}$ & $44.9 \pm 4.4$ & $45.1 \pm 6.6$ & $43.7 \pm 5.3$ \\
\hline Malondialdehyde $(\mathrm{mM}) \pm \mathrm{SD}$ & $5.3 \pm 0.8$ & $5.2 \pm 1.0$ & $5.4 \pm 0.7$ \\
\hline
\end{tabular}

Baseline measurements were not significantly different $(p>0.05)$ between the treatment groups for either the characteristics of the group or biochemical data.

MALTD: maltodextrin; Vit E: vitamin E; ZAM: zeolite.

Figure 1. The effect of zeolite on levels of plasma antioxidant capacity in plasma of human cigarette smokers.

The letters $a$ and $b$ indicate significant differences $(p<0.05)$ between zeolite and maltodextrin, between vitamin $\mathrm{E}$ and maltodextrin, respectively.

MALTD: maltodextrin; Vit E: vitamin E; ZAM: zeolite.

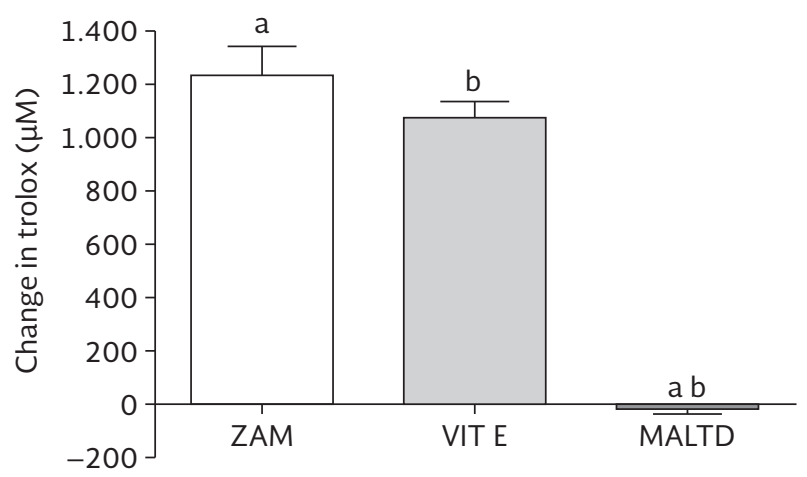

\section{DISCUSSION}

Free radicals are produced in excess during mitochondrial respiration and can react with biomolecules, altering their functions ${ }^{2,6}$. This molecular damage can be minor in healthy subjects because the free radicals can be trapped or neutralized by the subject's natural antioxidant systems ${ }^{1,3,4}$. However, the antioxidant system can be overwhelmed by increases in certain factors, including age, sedentary lifestyle, weight, and smoking ${ }^{1,3}$. Oxidative stress is exacerbated in smokers ${ }^{3}$, and smoking is a proven risk factor for cancer, respiratory disease, and circulatory
Figure 2. The effect of zeolite on catalase activity in plasma of human cigarette smokers.

The letters $a$ and $b$ indicate significant differences $(p<0.05)$ between zeolite and maltodextrin, between vitamin $\mathrm{E}$ and maltodextrin, respectively.

MALTD: maltodextrin; Vit E: vitamin E; ZAM: zeolite.

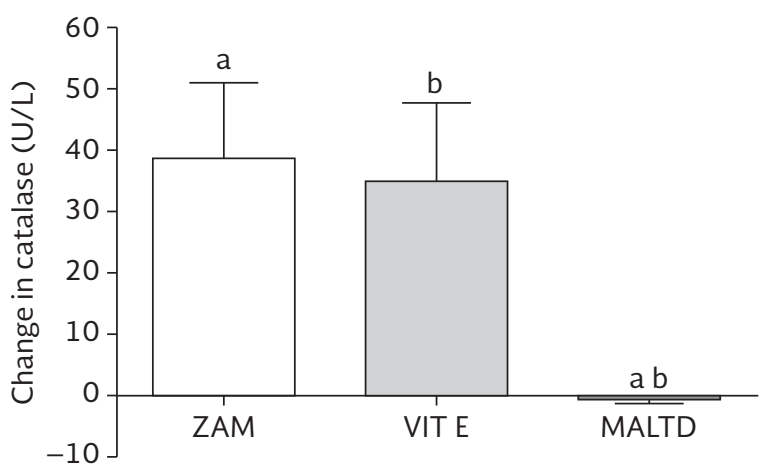

disease because the free radicals in smoke enhance oxidative stress ${ }^{1,2}$.

Although the prevalence of coronary heart disease is staggering, many of its risk factors are ultimately preventable through a healthy diet, exercise, and other positive lifestyle habits ${ }^{24}$. Of these, cigarette smoking is considered to be the most significant. As the number-one cause of preventable death, it is estimated that smoking is responsible for over 440,000 heartrelated deaths every year in the USA ${ }^{25}$. In Mexico, over 38 million people have smoked at least once in their lives (two men to every woman). In 2011, 17.3 million 
Figure 3. The effect of zeolite on hydrogen peroxide levels in plasma of human cigarette smokers.

The letters $a$ and $b$ indicate significant differences $(p<0.05)$ between zeolite and maltodextrin, between vitamin $\mathrm{E}$ and maltodextrin, respectively.

MALTD: maltodextrin; Vit E: vitamin E; ZAM: zeolite.

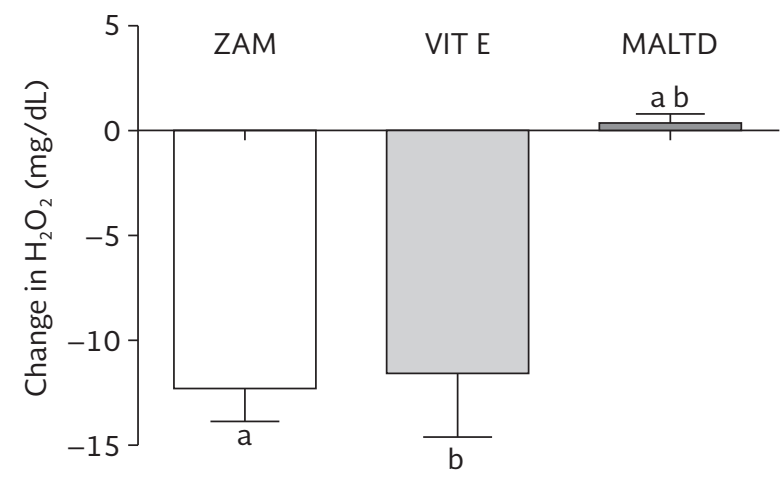

Mexicans between 12 and 65 years of age were active smokers ( 12 million men and 5.2 million women). Mexico City had the highest numbers of smokers in the country, with $30.8 \%$, followed by the western region of Mexico, with $24.7 \%$. The lowest percentage of smokers is in the south, between 14 and $18 \%^{26}$.

There is also evidence to suggest a strong relationship between that of passive smoke exposure, or secondhand smoke, and the development of coronary heart disease $(\mathrm{CHD})^{25,27-29}$. It is now widely considered that exposure to tobacco smoke increases the risk of $\mathrm{CHD}$ by $25-30 \%$, making it imperative to find alternative prevention methods for both active as well as passive smokers ${ }^{26}$. The ability of zeolites to absorb molecules of particular sizes has been used in medicine due to their anti-carcinogen and antioxidant properties, among others. As shown in previous reports, zeolites have high levels of antioxidant activity based on their capacity to scavenge free radicals and to inhibit lipoperoxidation ${ }^{16,17}$.

To our knowledge, this is the first clinical study that measures the effects of oral supplementation with zeolite on the oxidative stress levels of smokers. We observed that zeolite was as effective as vitamin E in reducing oxidative stress and this was achieved without any adverse effects on the study subjects. Thus, zeolites may be considered as an alternative way to attenuate oxidative stress, not only in smokers, but also in any disease that involves the generation of
Figure 4. The effect of zeolite on lipid peroxidation levels as measured by the production of malondialdehyde using the thiobarbituric acid reactive substances method in plasma of human cigarette smokers.

The letters $a$ and $b$ indicate significant differences $(p<0.05)$ between zeolite and maltodextrin, between vitamin $\mathrm{E}$ and maltodextrin, respectively.

MALTD: maltodextrin; Vit E: vitamin E; ZAM: zeolite.

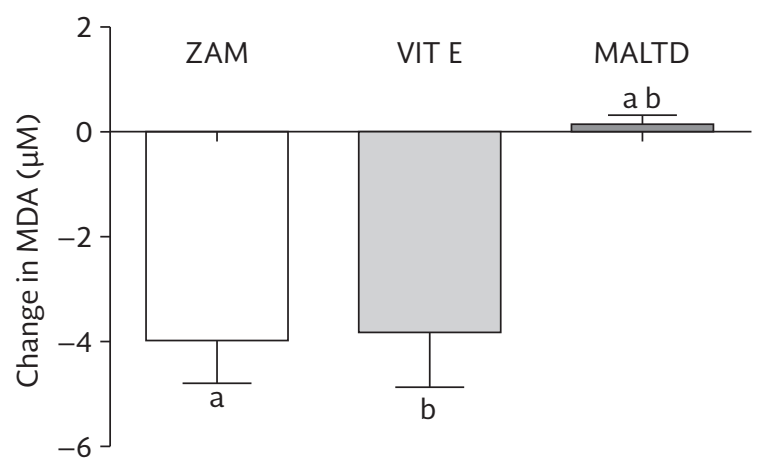

oxidative stress $12,13,16,17,29$. Because of the great heterogeneity in the intensity and time span of smoking (smoking time: 2-37 years; number of cigarettes per day: 8-29), it is difficult to make an analysis of the effectiveness of zeolites for different durations of this addiction. The limitations of the study are the number of subjects included and the number of ZAM determinations, making it worthwhile to expand this research to larger populations and with more testing to confirm the promising results observed from this pilot study. Furthermore, including a control group of non-smokers would be useful to assess the degree to which zeolites reverse the oxidative stress of smoking so that its effectiveness can be fully evaluated. Eventually, it would be valuable to clarify the mechanisms of action of the zeolite compounds.

In conclusion, the activated and micronized zeolite tested here (ZAM), acted as a modulator of oxidative stress in smokers when it was orally administered daily for 30 days. ZAM significantly improved the plasma antioxidant capacity and the enzymatic antioxidant system and decreased the $\mathrm{H}_{2} \mathrm{O}_{2}$ production and lipid peroxidation levels in smokers.

\section{ACKNOWLEDGEMENTS}

We thank Pedro Álvarez Cervantes, Deviani García Pérez, and Maria Fernanda Resendiz Otero for their assistance in the preparation of this article. This work was supported by 
CONACYT (grant SALUD-2010-01-142035 PDC Problemas Nacionales PDCPN2013-018), Mexico.

\section{REFERENCES}

1. Alberg AJ. The influence of cigarette smoking on circulating concentrations of antioxidant micronutrients. Toxicology. 2002; 180:121-37.

2. Asmus K, Bonifacic M. Free radical chemistry. In: Sen CK, Packer $\mathrm{L}$, Hänninen $\mathrm{O}$, eds. Handbook of Oxidants and Antioxidants in Exercise. Amsterdarm: Elsevier; 2000. p. 3-54.

3. Bloomer RJ, Solis AD, Fisher-Wellman KH, Smith WA. Postprandial oxidative stress is exacerbated in cigarette smokers. $\mathrm{Br}$ J Nutr. 2008;99:1055-60.

4. Hemalatha A, Venkatesan A, Bobby Z, Selvaraj N, Sathiyapriya $V$. Antioxidant response to oxidative stress induced by smoking. Indian J Physiol Pharmacol. 2006;50:416-20.

5. Lledías F, Rangel P, Hansberg W. Oxidation of catalase by singlet oxygen. J Biol Chem. 1998;273:10630-7.

6. Chakravati B, Chakravati DN. Oxidative modification of proteins: Age-related changes. Gerontology. 2007;53:128-39.

7. Bruno RS, Leonard SW, Atkinson J, et al. Faster plasma vitamin E disappearance in smokers is normalized by vitamin $C$ supplementation. Free Radic Biol Med. 2006;40:689-97.

8. Gloxhuber C, Potokar M, Pittermann W, et al. Zeolithe A-A phosphate substitute for detergents: toxicological investigation. Food Chem Toxicol. 1983;21:209-20.

9. Pond WG, Yen JT, Crouse JD. Tissue mineral element content in swine fed clinoptilolite. Bull Environ Contam Toxicol. 1989;42: 735-42.

10. Rodríguez-Fuentes G. Enterex: anti-diarrheic drug based on purified natural clinoptilolite. Zeolites. 1997:19:441-8.

11. Meier WM, Siegmann K. Significant reduction of carcinogenic compounds in tobacco smoke by the use of zeolite catalyst. Micropor Mesopor Mat. 1999;33:307-10.

12. Zarkovic N, Zarkovic K, Kralj M, et al. Anticancer and antioxidative effects of micronized zeolite clinoptilolite. Anticancer Res. 2003;23:1589-95.

13. Ivkovic S, Deutsch U, Silberbach A, Walraph E, Mannel M. Dietary supplementation with the tribomechanically activated zeolite clinoptilolite in immunodeficiency: effects on the immune system. Adv Ther. 2004;21:135-47.

14. Rodríguez-Fuentes G, Denis AR, Barrios-Álvarez MA, IraizozColarte A. Antacid drug based on purified natural clinoptilolite. Micropor Mesopor Mat. 2006;94:200-7.

15. Grancarić AM, Tarbuk A, Kovaček I. Nanoparticles of activated natural zeolite on textiles for protection. CI\&CEQ. 2009;15:203-10.
16. Montinaro M, Uberti D, Maccarinelli G, Bonini SA, Ferrari-Toninelli G, Memo M. Dietary zeolite supplementation reduces oxidative damage and plaque generation in the brain of an Alzheimer's disease mouse model. Life Sci. 2013;92:903-10.

17. Potgieter W, Samuels CS, Snyman JR. Potentiated clinoptilolite: artificially enhanced aluminosilicate reduces symptoms associated with endoscopically negative gastroesophageal reflux disease and nonsteroidal anti-inflammatory drug induced gastritis Clin Exp Gastroenterol. 2014;7:215-20.

18. Mumpton FA. La roca magica: uses of natural zeolites in agriculture and industry. Proc Natl Acad Sci USA. 1999;96:3463-70.

19. Sersale R. Natural zeolites: processing, present and possible applications. Stud Surf Sci Catal. 1985;24:503-12.

20. Naber JE, De Jong KP, Stork WH, Kuipersa HP, Postb MF. Industrial applications of zeolite catalysts. Stud Surf Sci Catal. 1994; 84:2197-219.

21. Kyriakis SC, Papaioannou DS, Alexopoulos C, Polizopoulouc, Tzikaa ZE, Kyriakisa CS. Experimental studies on safety and efficacy of the dietary use of a clinoptilolite-rich tuff in sows: a review of recent research in Greece. Micropor Mesopor Mat. 2002;51:65-74.

22. Gregg SJ, Sing KSW. Adsorption, Surface Area and Porosity $2^{\text {nd }}$ Ed. San Diego, CA: Academic Press Inc. 1982.

23. Dogliotti G, Malavazos AE, Giacometti S, et al. Natural zeolite chabazite/phillipsite/analcime increase blood levels of antioxidant enzymes. J Clin Biochem Nutr. 2012;50:195-8.

24. Barnoya J, Glantz SA. Cardiovascular effects of secondhand smoke: nearly as large as smoking. Circulation. 2005;111: 2684-98.

25. U.S. Department of Health and Human Services, Centers for Disease Control and Prevention, National Center for Chronic Disease Prevention and Health Promotion, Office on Smoking and Health. 2014. The Health Consequences of Smoking-50 Years of Progress. A Report of the Surgeon General; c2016 Available at: http://www.surgeongeneral.gov/library/reports/50-yearsof-progress/ [Accessed 2015 Aug 17].

26. Instituto Nacional de Psiquiatría Ramón de la Fuente Muñiz (INPRFM). Encuesta Nacional de Adicciones 2011: Reporte de Tabaco $1^{\text {a }}$ ed. 2012. Available at: http://www.conadic.salud.gob. $\mathrm{mx} / \mathrm{pdfs} /$ ENA_2011_TABACO.pdf [Accessed 08/04/2015]

27. Faught BE, Flouris AD, Cairney J. Epidemiological evidence associating secondhand smoke exposure with cardiovascular disease. Inflamm Allergy Drug Targets. 2009;8:321-7.

28. Oberg M, Jaakkola MS, Woodward A, Peruga A, Prüss-Ustün A. Worldwide burden of disease from exposure to second-hand smoke: a retrospective analysis of data from 192 countries. Lancet. 2011;377:139-46

29. Laurino C, Palmieri B. Zeolite: "the magic stone"; main nutritional, environmental, experimental and clinical fields of application. Nutr Hosp. 2015;32:573-81. 